\title{
Análise da Percepção de Acadêmicos sobre o Ensino de Urgência e Emergência em Curso Médico
}

\author{
Analysis of the Perception of Academics about Emergency and \\ Emergency Medical Education
}

\author{
Érica Manuela da Silva Boa Sorte ${ }^{1}$ (D) \\ Jéssica Novais Fonseca da Silva ${ }^{\mathrm{I}}(\mathrm{D})$ \\ Carlos Gabriel dos Santos ${ }^{1}$ (ID \\ Paula Dandara Correia de Pinho ${ }^{\mathrm{I}}$ (D) \\ Jairo Evangelista Nascimento ${ }^{\mathrm{I}}$ (i) \\ Claudiojanes Reis ${ }^{\mathrm{I}}(\mathrm{B}$
}

\section{PALAVRAS-CHAVE}

- Medicina de Emergência.

- Atendimento Pré-Hospitalar.

- Educação Médica.

- Atendimento de Urgência.
Introdução: $O$ atendimento em urgência e emergência (UE) envolve situações de risco que exigem intervenção imediata para aumentar as chances de sobrevivência do paciente. O ensino dessa disciplina durante a graduação de Medicina não tem sido efetivo, e os alunos apresentam deficiência no atendimento, tornando-se importante realizar avaliação para conhecer a realidade sobre esse processo formativo. O objetivo deste estudo foi avaliar o conhecimento e a satisfação pessoal dos acadêmicos de Medicina que se encontram no internato quanto à disciplina de Urgência e Emergência, em faculdade privada do norte de Minas Gerais. Método: Trata-se de um estudo transversal, quantitativo e descritivo, com aplicação de 185 questionários que abordaram dados demográficos, conhecimento da política de atenção à UE aplicada ao Samu, conhecimento da epidemiologia dos atendimentos pré-hospitalares do Samu, avaliação e conduta durante o atendimento, e percepção do ensino de UE. A população foi constituída por estudantes de Medicina, do oitavo ao $12^{\circ}$ período, divididos em dois grupos em relação ao estágio em UE. Realizou-se análise estatística por meio do teste qui-quadrado de Pearson ou exato de Fisher com significância $p<0,05$. Resultados: A população foi predominantemente do sexo feminino. Quanto à opção de trabalho, 123 (66,5\%) dos estudantes optaram por consultório médico, $35,1 \%$ escolheram os serviços de UE, e 95 (51,4\%) citaram a saúde da família. Quanto aos profissionais que compõem a ambulância básica ou avançada, 40,5\% e 54,1\% acertaram a composição da básica e avançada, respectivamente, sendo estatisticamente significante com p-valor 0,001 e 0,002. Dos participantes do estudo, $15,7 \%$ marcaram corretamente todas as causas de atendimento pelo Samu, e 36,2\% acertaram a natureza clínica como a maior demanda de atendimento. Não houve diferenças estatísticas quanto à percepção da importância do conhecimento do médico generalista sobre UE. Quanto à percepção dos acadêmicos em relação à própria formação, foi identificada diferença estatística nas questões relacionadas às temáticas triagem - Protocolo de Manchester, monitorização, suporte básico e avançado de vida, e emergências pediátricas. Conclusões: O ensino de UE, na percepção dos alunos, mostra-se efetivo nessa avaliação, mas com lacunas em urgências pediátricas e toxicológicas. Os alunos formam-se inseguros quanto ao atendimento nessa área. Há a necessidade de discutir mais essa temática por causa da relevância dela para a prática profissional. 


\section{KEYWORDS}

- Emergency Medicine.

- Prehospital Care.

- Medical Education.

- Urgent Care.

\section{ABSTRACT}

Introduction: Urgency and emergency service involves risk situations that require immediate intervention to increase the patient's chances of survival. The teaching of this discipline during undergraduate medical school has not been effective and the students show deficient training; thus, carrying out an evaluation aiming to know the reality about this formative process becomes important. Objectives: to evaluate the knowledge and personal satisfaction of the undergraduate medical students attending internship regarding the discipline of Urgency and Emergency, in private medical schools in the North of Minas Gerais. Method: transversal, quantitative, descriptive study, which applied 185 questionnaires addressing demographic data; knowledge of the Urgency and Emergency care policy applied to SAMU; knowledge of the epidemiology of pre-hospital care at SAMU, assessment and conduct during care; and perception of UE education. The population consisted of medical students, from the $8^{\text {th }}$ to the $12^{\text {th }}$ periods of medical school, divided into two groups in relation to the internship in UE. The statistical analysis was performed using Pearson's Chi-square test or Fisher's exact test, with significance set at $p<0.05$. Results: The population was predominantly female. As for the job option, 123 (66.5\%) chose working at a doctor's office, 35.1\% chose UE services, and 95 (51.4\%) cited family health. As for the professionals who work at the basic or advanced ambulance, $40.5 \%$ and $54.1 \%$ agreed on the composition of the basic and advanced ambulances, respectively. Being statistically significant with a p-value of 0.001 and $0.002 .15 .7 \%$ correctly answered all causes of care provided by SAMU, and 36.2\% correctly answered the clinical nature as the highest demand for care. There were no statistical differences regarding the perception of the importance of the general practitioner's knowledge of urgency and emergency. Regarding the perception of students in relation to their training, a statistical difference was identified in questions related to the topics Screening - Manchester protocol, Monitoring, Basic and advanced life support, Pediatric emergencies. Conclusions: the urgency and emergency teaching, according to the students' perception, is effective in this evaluation, but has gaps in pediatric and toxicological emergencies. Students are unsure of how to work in this area. It is necessary to further discuss this topic, due to its relevance to professional practice.

Recebido em 31/1/20

Aceito em $1 / 4 / 20$

\section{INTRODUÇÃO}

Urgência e emergência (UE) são termos utilizados na prática médica para descrever situações, seja de natureza clínica ou traumática, que exigem intervenção imediata a fim de reduzir a morbimortalidade do paciente e aumentar suas chances de sobrevida ${ }^{1,2}$.

O ensino dessa matéria nas escolas de Medicina apresenta lacunas, de modo que os alunos recém-formados se sentem inseguros e muitas vezes tecnicamente despreparados para o atendimento desse tipo de ocorrência ${ }^{3,4}$. Paradoxalmente, após a conclusão do curso de Medicina, grande parte dos alunos, antes mesmo de ingressar em cursos de residência médica ou especialização, acaba trabalhando em setores de $\mathrm{UE}^{5,6}$, fato comprovado pelo Conselho Federal de Medicina (CFM) ${ }^{7}$. Até pouco tempo atrás, tal matéria não fazia parte obrigatória do currículo de muitas escolas ${ }^{5,8}$, enquanto o cenário enfrentado por esses médicos é de aumento na prevalência de casos de UE, visto que há uma elevação na expectativa de vida, na sobrevida de pacientes com doenças crônicas e no número de acidentes de trânsito e de violência interpessoal ${ }^{5,79}$.

Em 2013, a Lei $n^{\circ} 12.871$ passou a exigir que na graduação de Medicina houvesse pelo menos $30 \%$ da carga horária do internato destinada às atividades na atenção básica e em serviços de UE do Sistema Único de Saúde (SUS) $)^{1,5,6,8}$. Nesse período, os alunos devem praticar suas habilidades por meio de treinamento intensivo em unidades de pronto atendimento (UPAs) ${ }^{5,8}$.

São vários os fatores associados à deficiência de ensino da UE nas faculdades de Medicina no Brasil, como: falta de convênio entre instituições de ensino superior (IES) com pronto-socorro externo; ausência deste, nos hospitais universitários, para prática dos alunos em casos reais; alto custo dos laboratórios com manequins e equipamentos adequados; falta de profissionais capacitados para o ensino desse tema; e fragmentação das áreas envolvidas em UE ${ }^{5-8}$.

Além desses fatores, há que se considerar o método de ensino que deve ser analisado no que tange à lacuna na formação de UE. Em países europeus e norte-americanos, é muito utilizado o método conhecido por Educação Médica Baseada em Simulação (EMBS) que adota várias ferramentas para mimetizar situações reais ${ }^{10}$ e avaliar as habilidades técnicas e teóricas dos graduandos em Medicina ${ }^{4,5,10-12}$, as quais permitem ao acadêmico aprender com base no contato direto com as situações de emergência, sem, no entanto, oferecer riscos a pacientes reais, já que o treinamento ocorre em ambientes seguros ${ }^{13-15}$.

Com base nos aspectos observados e sabendo que quanto mais se ampliam os conhecimentos desse tema, estendendo-os inclusive à população leiga, mais pessoas podem ser salvas em cenas de risco, este trabalho visou analisar o conhecimento e a percepção sobre o ensino de UE entre os acadêmicos de Medicina, em diferentes estágios do internato, em faculdade privada, localizada em cidade de médio porte do norte de Minas Gerais.

\section{METODOLOGIA}

Trata-se de um estudo de caráter transversal, quantitativo, com análise descritiva dos dados, realizado em instituição privada de ensino de Montes Claros, em Minas Gerais, durante o segundo semestre de 2017.

O público-alvo incluiu acadêmicos do oitavo período ao $12^{\circ}$ período 
do curso médico da instituição, por meio de amostra censitária, os quais foram divididos em dois grupos em relação ao estágio em UE, sendo: estágio inicial (oitavo e nono períodos) e estágio avançado (décimo, $11^{\circ}$ e $12^{\circ}$ períodos). A seleção dos períodos relacionou-se aos acadêmicos devidamente matriculados que cursavam os estágios do internato ou se preparavam para realizá-lo. Foram incluídos os acadêmicos que concordaram, por meio do Termo de Consentimento Livre e Esclarecido (TCLE), em responder ao questionário e estavam presentes em uma das três tentativas para a coleta de dados. O público-alvo estimado era de 250 acadêmicos.

Utilizou-se questionário autoaplicável, adaptado de Dias ${ }^{1}$, Horta et al. ${ }^{16}$ e Oliveira, Santos e Zeitoun ${ }^{17}$, composto de 34 questões subjetivas e objetivas que tinham por objetivo avaliar o ensino de UE em suas diversas abrangências. O questionário foi organizado em quatro domínios principais: dados demográficos (três questões), conhecimento da política de atenção à UE aplicada ao Serviço de Atendimento Móvel de Urgência - Samu (oito questões), conhecimento da epidemiologia dos atendimentos pré-hospitalares realizados pelo Samu, avaliação e conduta durante o atendimento (seis questões), e percepção do ensino de UE por domínios (17 questões). Realizaram-se o teste e o reteste do questionário, com intervalo de dez dias, com um grupo de dez acadêmicos, que não foram incluídos na amostra final, a fim de avaliar e melhorar a compreensão e conteúdo dele.

Após coleta, tabularam-se as informações e realizou-se a análise descritiva por meio do Microsoft Excel $^{\circledR}$, que permitiu a construção de um banco de dados para efetuar a análise estatística, feita a partir do programa SPSS 17.0, por meio do teste qui-quadrado de Pearson ou exato de Fisher quando mais adequado com $\mathrm{p}<0,05$. O estudo foi realizado mediante aprovação do projeto pelo Comitê de Ética, com o Certificado de Apresentação para Apreciação Ética (CAAE) no 70008917.4.0000.5141.

\section{RESULTADOS}

Em relação à amostra, foi contabilizado um total de 185 alunos, com perda de $24 \%$ da amostra prevista, sendo essa perda relacionada aos acadêmicos em estágio no momento da coleta de dados. Dos 185 acadêmicos que responderam ao questionário aplicado, a maioria era do sexo feminino (63,2\%) e com idade entre 20 e 24 anos (54,4\%), e a maior parte $(26,5 \%)$ estava cursando o décimo período, enquanto o menor número $(13,5 \%)$ foi obtido do nono período (Tabela 1). Questionados sobre em que área pretendiam trabalhar logo após a formatura, 123 $(66,5 \%)$ optaram por consultório médico, $35,1 \%$ escolheram os serviços de UE, e 95 (51,4\%) citaram a Estratégia Saúde da Família (ESF), sendo a maior parte do estágio avançado. Esse resultado é estatisticamente significante com p-valor $=0,001$ (Tabela 2). Sobre a empregabilidade, $87 \%$ afirmaram que é mais fácil conseguir emprego em ESF e $38,4 \%$ em serviços de UE (Tabela 1).

Sobre o domínio conhecimento da política de atenção à UE aplicada ao Samu, observou-se que, em relação à quantidade de habitantes de um município preconizada para atendimento por uma ambulância do tipo unidade de suporte básico (USB), somente 17 (9,2\%) se aproximaram da resposta correta ao apontarem valores entre 100 mil e 150 mil. A mesma pergunta foi feita para a ambulância do tipo unidade de suporte avançado (USA), e apenas seis $(3,2 \%)$ acadêmicos, em estágio avançado, indicaram valores corretos, entre 400 mil e 450 mil (Tabela 2).

Quanto aos profissionais que compõem os dois tipos de ambulâncias supracitados, $75(40,5 \%)$ acertaram ao afirmarem que o condutor e o técnico de enfermagem compõem a USB, enquanto $100(54,1 \%)$ acertaram os componentes da USA (condutor, enfermeiro e médico), com predomínio de acerto para os acadêmicos em estágio avançado em ambas as respostas, sendo estatisticamente significante com $p$-valor 0,001 e 0,002 , respectivamente (Tabela 2). Foram ainda questionados em relação ao material presente nas ambulâncias, havendo apenas cinco acertos para a USB e 110 para a USA, que citaram somente os materiais corretos (Tabela 2). No entanto, observou-se, em relação à USB, que, nas respostas, $182(98,4 \%)$ acadêmicos citaram o material de imobilização e 124 (67\%) o aspirador de secreções, porém associados a outros materiais não obrigatórios, como monitor e desfibrilador cardíaco, mencionados por $130(70,3 \%)$ estudantes. Quanto à USA, mais de $90 \%$ dos alunos marcaram as opções que incluíam material de imobilização 179 (96,8\%),

\begin{tabular}{|c|c|c|}
\hline \multicolumn{3}{|c|}{$\begin{array}{c}\text { Tabela } 1 \\
\text { Caracterização dos acadêmicos participantes da pesquisa, segundo } \\
\text { características individuais, período do curso e perspectiva } \\
\text { profissional, Brasil, } 2017(\mathrm{n}=185)\end{array}$} \\
\hline Variável & $\mathbf{n}$ & $\%$ \\
\hline \multicolumn{3}{|l|}{ Idade (anos) } \\
\hline $20-24$ & 99 & 54,4 \\
\hline $25-29$ & 64 & 35,2 \\
\hline $30-34$ & 16 & 8,8 \\
\hline $35-39$ & 1 & 0,5 \\
\hline$>39$ & 2 & 1,1 \\
\hline \multicolumn{3}{|l|}{ Sexo } \\
\hline Feminino & 117 & 63,2 \\
\hline Masculino & 68 & 36,8 \\
\hline \multicolumn{3}{|l|}{ Período cursado } \\
\hline $8^{\circ}$ & 42 & 22,7 \\
\hline $9^{\circ}$ & 25 & 13,5 \\
\hline $10^{\circ}$ & 49 & 26,5 \\
\hline $11^{\circ}$ & 32 & 17,3 \\
\hline $12^{\circ}$ & 37 & 20,0 \\
\hline \multicolumn{3}{|l|}{ Local onde pretende trabalhar } \\
\hline Consultório médico & 123 & $66,5 \%$ \\
\hline Hospital & 104 & $56,2 \%$ \\
\hline ESF & 95 & $51,4 \%$ \\
\hline UTI & 31 & $16,8 \%$ \\
\hline Serviços de UE & 65 & $35,1 \%$ \\
\hline \multicolumn{3}{|l|}{ Onde julga mais fácil empregar } \\
\hline Consultório médico & 9 & $4,9 \%$ \\
\hline Hospital & 63 & $34,1 \%$ \\
\hline ESF & 161 & $87,0 \%$ \\
\hline UTI & 7 & $3,8 \%$ \\
\hline Serviços de UE & 71 & $38,4 \%$ \\
\hline Outro & 3 & $1,6 \%$ \\
\hline
\end{tabular}

Fonte: Elaborada pelos autores

$3 \mid$\begin{tabular}{l|l} 
REVISTA BRASILEIRA DE EDUCAÇÃO MÉDICA \\
\hline 44 (3) : e075; 2020
\end{tabular} 
aspirador de secreções 170 (91,9\%), material de intubação endotraqueal $(98,4 \%)$ e monitor e desfibrilador cardíaco $182(98,9 \%)$, ao passo que a maior parte dos erros - 67 dos acadêmicos $(36,2 \%)$ - relacionou-se à não escolha da opção incubadora para recém-nascidos como material da unidade.

\section{Tabela 2}

Distribuição dos acadêmicos em estágios inicial e avançado em UE e

a relação com o conhecimento da política de atenção à UE aplicada ao

Samu e da epidemiologia dos atendimentos pré-hospitalares realizados pelo Samu, a avaliação e conduta durante o atendimento, e percepção do ensino de UE por domínios, Brasil 2017 (n = 185)

\section{Nível do estágio em UE}

Variáveis

$\begin{array}{cc}\text { Estágio inicial } & \text { Estágio avançado } \\ \mathbf{n}(\%) & \mathbf{n}(\%)\end{array}$

\section{Conhecimento da política de atenção à UE aplicada ao Samu}

Número de habitantes por ambulância do tipo unidade de suporte básico

$\begin{array}{cccc}\text { Acerto } & 4(7,5) & 13(11,6) & \\ \text { Erro } & 49(92,5) & 99(88,4) & 0,423\end{array}$

Número de habitantes por ambulância do tipo unidade de suporte avançado

$\begin{array}{cccc}\text { Acerto } & 0(0) & 6(5,4) & \\ \text { Erro } & 52(100) & 106(94,6) & 0,178^{*}\end{array}$

Profissionais que compõem a unidade de suporte básico

$\begin{array}{llll}\text { Acerto } & 16(23,9) & 59(50) & \\ \text { Erro } & 51(76,1) & 59(50) & 0,001\end{array}$

Profissionais que compõem a unidade de suporte avançado

$\begin{array}{lll}\text { Acerto } & 26(38,8) & 74(62,7) \\ \text { Erro } & 41(61,2) & 44(37,3)\end{array}$

0,002

Materiais que compõem a unidade de suporte básico

$\begin{array}{cccc}\text { Acerto } & 1(1,5) & 4(3,4) & \\ \text { Erro } & 66(98,5) & 114(96,6) & 0,655^{*}\end{array}$

Materiais que compõem a unidade de suporte avançado

$\begin{array}{lll}\text { Acerto } & 41(61,2) & 69(58,5) \\ \text { Erro } & 26(38,8) & 49(41,5)\end{array}$

Conhecimento da epidemiologia dos atendimentos pré-hospitalares realizados pelo Samu e avaliação e conduta durante o atendimento

Condições com necessidade de atendimento pelo Samu

$\begin{array}{cccc}\text { Acerto } & 6(9) & 23(19,7) & \\ \text { Erro } & 61(91) & 94(80,3) & 0,055\end{array}$

Principais condições atendidas pelo Samu

$\begin{array}{cll}\text { Acerto } & 16(24,6) & 51(46,8) \\ \text { Erro } & 49(75,4) & 58(53,2)\end{array}$

Sinais clínicos de uma parada cardiorrespiratória (PCR)

$\begin{array}{llll}\text { Acerto } & 21(31,3) & 51(43,6) & \\ \text { Erro } & 46(68,7) & 66(56,4) & 0,101\end{array}$

Ritmos cardíacos de PCR chocáveis

$\begin{array}{cccc}\text { Acerto } & 48(71,6) & 107(90,7) & \\ \text { Erro } & 19(28,4) & 11(9,3) & 0,001\end{array}$

\begin{tabular}{|c|c|c|c|}
\hline \multicolumn{4}{|c|}{$\begin{array}{c}\text { Tabela } 2 \\
\text { Continuação }\end{array}$} \\
\hline \multicolumn{4}{|c|}{ Nível do estágio em UE } \\
\hline Variáveis & $\begin{array}{l}\text { Estágio inicial } \\
\quad \mathrm{n}(\%)\end{array}$ & $\begin{array}{c}\text { Estágio avançado } \\
\text { n (\%) }\end{array}$ & p-valor \\
\hline \multicolumn{4}{|c|}{$\begin{array}{l}\text { Conhecimento da epidemiologia dos atendimentos pré-hospitalares realizados } \\
\text { pelo Samu e avaliação e conduta durante o atendimento }\end{array}$} \\
\hline \multicolumn{4}{|c|}{$\begin{array}{l}\text { Sequência de atendimento de emergência, segundo o algoritmo do suporte } \\
\text { básico de vida }\end{array}$} \\
\hline Acerto & $25(39,7)$ & $30(25,9)$ & \\
\hline Erro & $38(60,3)$ & $86(74,1)$ & 0,056 \\
\hline
\end{tabular}

Relação entre compressões torácicas e ventilações em PCR em adultos assistida por dois socorristas

\begin{tabular}{|c|c|c|}
\hline Acerto & $57(85,1)$ & $103(88)$ \\
\hline Erro & $10(14,9)$ & $14(12)$ \\
\hline
\end{tabular}

Frequência recomendada por minuto de compressões torácicas em vítima de PCR

$\begin{array}{cll}\text { Acerto } & 25(40,3) & 35(30,4) \\ \text { Erro } & 37(59,7) & 80(69,6)\end{array}$
0,185

Profundidade adequada das compressões torácicas aplicadas em vítima de PCR

$$
\begin{array}{ccc}
\text { Acerto } & 16(24,6) & 15(13) \\
\text { Erro } & 49(75,4) & 100(87)
\end{array}
$$

0,048

Percepção do ensino de UE por domínios e da sua importância

Percepção da formação em relação à triagem - Protocolo de Manchester

$$
\text { Adequada } \quad 4(6) \quad 22(19)
$$

Parcialmente adequada 23(34,3) 52(44,8)

Inadequada 40(59,7) 42(36,2)

0,003

Percepção da formação em relação à monitorização

$\begin{array}{ccc}\text { Adequada } & 17(25,4) & 43(37,1) \\ \text { Parcialmente adequada } & 26(38,8) & 63(54,3) \\ \text { Inadequada } & 24(35,8) & 10(8,6)\end{array}$

0,000

Percepção da formação em relação ao suporte básico de vida

$\begin{array}{ccc}\text { Adequada } & 22(32,8) & 51(43,2) \\ \text { Parcialmente adequada } & 44(65,7) & 55(46,6) \\ \text { Inadequada } & 1(1,5) & 12(10,2)\end{array}$

Percepção da formação em relação ao suporte avançado de vida

$\begin{array}{ccc}\text { Adequada } & 8(11,9) & 28(23,9) \\ \text { Parcialmente adequada } & 47(70,1) & 58(49,6) \\ \text { Inadequada } & 12(17,9) & 31(26,5)\end{array}$

0,013

Percepção da formação em relação às emergências cardiovasculares e respiratórias

$\begin{array}{cccc}\text { Adequada } & 8(11,9) & 26(22,2) & \\ \text { Parcialmente adequada } & 51(76,1) & 76(65) & \\ \text { Inadequada } & 8(11,9) & 15(12,8) & 0,199\end{array}$

Percepção da sua formação em relação às emergências toxicológicas

$\begin{array}{cccc}\text { Adequada } & 3(4,5) & 11(9,3) & \\ \text { Parcialmente adequada } & 34(50,7) & 50(42,4) & \\ \text { Inadequada } & 30(44,8) & 57(48,3) & 0,350 \\ & & & \text { Continua... }\end{array}$




\begin{tabular}{|c|c|c|c|}
\hline \multicolumn{2}{|c|}{ Tabela 2} & \multicolumn{2}{|c|}{ Continuação } \\
\hline \multicolumn{4}{|c|}{ Nível do estágio em UE } \\
\hline Variáveis & $\begin{array}{l}\text { Estágio inicial } \\
\text { n (\%) }\end{array}$ & $\begin{array}{c}\text { Estágio avançado } \\
\mathrm{n}(\%)\end{array}$ & p-valor \\
\hline \multicolumn{4}{|c|}{ Percepção do ensino de UE por domínios e da sua importância } \\
\hline \multicolumn{4}{|c|}{ Percepção da formação em relação às emergências neurológicas } \\
\hline Adequada & $8(11,9)$ & $19(16,1)$ & \\
\hline Parcialmente adequada & $41(61,2)$ & $66(55,9)$ & \\
\hline Inadequada & $18(26,9)$ & $33(28)$ & 0,694 \\
\hline
\end{tabular}

Percepção da formação em relação às emergências endócrinas

$\begin{array}{cccc}\text { Adequada } & 2(3) & 8(6,8) & \\ \text { Parcialmente adequada } & 35(53) & 56(47,5) & \\ \text { Inadequada } & 29(43,9) & 54(45,8) & 0,499\end{array}$

Percepção da formação em relação às emergências pediátricas

$\begin{array}{ccc}\text { Adequada } & 1(1,5) & 22(18,8) \\ \text { cialmente adequada } & 22(32,8) & 58(49,6)\end{array}$

Inadequada

$44(65,7)$

$37(31,6)$

0,000

Percepção da formação em relação ao atendimento ao politraumatizado

$\begin{array}{cccc}\text { Adequada } & 11(16,4) & 32(27,1) & \\ \text { Parcialmente adequada } & 38(56,7) & 57(48,3) & \\ \text { Inadequada } & 18(26,9) & 29(24,6) & 0,249 \\ \text { Percepção do modelo de ensino de UE da instituição onde estuda } & \\ \text { Adequada } & 10(14,9) & 27(23,3) & \\ \text { Parcialmente adequada } & 48(71,6) & 67(57,8) & \\ \text { Inadequada } & 9(13,4) & 22(19) & 0,171\end{array}$

Percepção sobre a importância do conhecimento, pelo médico generalista, das situações médicas de UE

$\begin{array}{cccc}\text { Muito importante } & 65(97) & 116(99,1) & \\ \text { Importante } & 2(3) & 1(0,9) & 0,300^{*}\end{array}$

Realização de atividade extracurricular em EU

\begin{tabular}{cccc} 
Sim & $12(17,9)$ & $32(27,1)$ & \\
Não & $55(82,1)$ & $86(72,9)$ & 0,157 \\
\multicolumn{4}{c}{$\begin{array}{c}\text { Perspectiva profissional } \\
\text { Locais onde gostaria de trabalhar após a conclusão da graduação }\end{array}$} \\
Consultório médico & & \\
Não & $25(37,3)$ & $37(31,4)$ & \\
Sim & $42(62,7)$ & $81(68,6)$ & 0,409 \\
Hospital & & & \\
Não & $27(40,3)$ & $54(45,8)$ & 0,472 \\
Sim & $40(59,7)$ & $64(54,2)$ & \\
ESF & & & \\
Não & $43(64,2)$ & $47(39,8)$ & 0,122 \\
Sim & $24(35,8)$ & $71(60,2)$ & \\
UTI & & $102(86,4)$ & \\
Não & $52(77,6)$ & $15(22,4)$ & \\
Sim & & & \\
\hline
\end{tabular}

\begin{tabular}{|c|c|c|c|}
\hline \multicolumn{4}{|c|}{ Continuação } \\
\hline \multirow{3}{*}{ Variáveis } & \multicolumn{2}{|c|}{ Nível do estágio em UE } & \multirow{3}{*}{ p-valor } \\
\hline & $\begin{array}{c}\text { Estágio inicial } \\
\text { n (\%) }\end{array}$ & $\begin{array}{c}\text { Estágio avançado } \\
\text { n (\%) }\end{array}$ & \\
\hline & \multicolumn{2}{|c|}{ Perspectiva profissional } & \\
\hline \multicolumn{4}{|c|}{ Locais onde gostaria de trabalhar após a conclusão da graduação } \\
\hline \multicolumn{4}{|c|}{ Serviços de UE } \\
\hline Não & $45(67,2)$ & $75(63,6)$ & \\
\hline Sim & $22(32,8)$ & $43(36,4)$ & 0,622 \\
\hline
\end{tabular}

*Teste Exato de Fisher.

Fonte: Elaborada pelos autores

No domínio conhecimento da epidemiologia dos atendimentos pré-hospitalares realizados pelo Samu, avaliação e conduta durante o atendimento, constatou-se que apenas $29(15,7 \%)$ dos acadêmicos assinalaram todas as causas que demandam necessidade de atendimento pelo Samu (Tabela 2), e $136(73,5 \%)$ acertaram ao escolherem as alternativas que incluíam trabalho de parto iminente, e 162 (87,6\%), transferência com risco de vida. Os principais erros aconteceram nas respostas em que não foram assinalados os itens crise hipertensiva e crise de broncoespasmo ( 65 para cada tipo $=35,1 \%$ ) e queda da própria altura ( $88=47,6 \%)$ e tentativa de suicídio $(46=24,9 \%)$. Questionados sobre a principal natureza de atendimento, entre clínica e traumática, 67 (36,2\%) marcaram corretamente natureza clínica.

Quando indagados acerca dos sinais clínicos de uma parada cardiorrespiratória (PCR), o principal erro ocorreu na não seleção da perda da consciência $(68=36,8 \%)$ e na escolha de ausência de qualquer pulso $(49=26,5 \%)$. Quando questionados sobre os ritmos cardíacos característicos de PCR que requerem choque elétrico, obteve-se o maior percentual de acerto $(90,7 \%)$ para os acadêmicos em estágio avançado que selecionaram taquicardia ventricular e fibrilação ventricular, sendo estatisticamente significante com $p$-valor $=0,001$ (Tabela 2). Sobre o algoritmo do suporte básico de vida (SBV), 118 (63,8\%) afirmaram ser $A B C D$ a sequência correta, enquanto 55 (29,7\%) escolheram CABD com maior percentual de erro para os acadêmicos em estágio avançado (Tabela 2). Para a relação entre compressões e ventilação em PCR em adultos assistida por dois socorristas, 160 (87\%) acertaram ao escolherem 30:2; quanto à frequência e profundidade de compressões, houve acerto de $60(33,9 \%)$ e $31(17,2 \%)$, respectivamente, para quem citou os intervalos corretos entre 100 e 120 compressões por minuto com profundidade entre 5 e $6 \mathrm{~cm}$. No entanto, houve acertos parciais com respostas de valores específicos dentro desses intervalos, sendo $83(46,9 \%)$ acertos para o número e $124(68,9 \%)$ para a profundidade das compressões.

A dimensão percepção do ensino de UE por domínios constatou que $181(97,8 \%)$ alunos consideraram muito importante o conhecimento acerca da UE e $121(65,4 \%)$ afirmaram que esse conhecimento deve ser adquirido apenas durante a graduação. $\mathrm{Na}$ avaliação da satisfação pessoal do acadêmico com o curso de UE oferecido pela faculdade em que estuda, $82(44,3 \%)$ consideraram a formação em relação ao Protocolo de Manchester inadequada, e cerca de metade dos alunos afirmou que

$5 \mid$\begin{tabular}{l|l} 
REVISTA BRASILEIRA DE EDUCAÇÃO MÉDICA \\
\hline 44 (3) : e075; 2020
\end{tabular} 
é parcialmente adequado o ensino de monitorização (48,1\%), SBV $(53,5 \%)$, suporte avançado de vida (SAV) $(56,8 \%)$ e atendimento ao politraumatizado $(51,4 \%)$. Os discentes consideraram inadequado o ensino de emergências toxicológicas $(47 \%)$ e pediátricas $(43,8 \%)$. O ensino de emergências cardiológicas, neurológicas e endocrinológicas foi conceituado como parcialmente adequado (Tabela 2).

De modo geral, $115(62,2 \%)$ consideraram o ensino de UE na instituição analisada como parcialmente adequado, ao passo que 37 (20\%) afirmaram que é adequado (Tabela 2).

Outras variáveis correlacionadas aos domínios citados e o nível do estágio em UE são apresentados na Tabela 2.

\section{DISCUSSÃO}

Existem lacunas quanto ao conhecimento sobre a política de UE relacionada ao Samu e sobre a epidemiologia dos atendimentos préhospitalares realizados por esse serviço, avaliação e conduta durante o atendimento.

A UE é uma importante etapa na formação do profissional médico ${ }^{1,5,8,16,18,19}$, e a própria Organização Mundial da Saúde (OMS) recomenda que essa etapa faça parte do currículo de profissionais da área $^{13}$. Tal fato foi constatado no presente estudo: $97,8 \%$ dos discentes afirmaram que o conhecimento de UE é muito importante, pois trata-se de um componente imprescindível para a formação do futuro médico. Dos alunos que participaram da pesquisa, 38,4\% afirmaram que, após a conclusão da curso, pretendem trabalhar em serviços de UE.

De acordo com a maioria dos estudantes que participaram da pesquisa, é necessário que tais temas sejam ensinados precocemente durante a formação. Talvez isso possa ter relação com a maior valorização dada ao assunto, com o acadêmico vendo a necessidade de aplicar a UE cada vez mais cedo em sua prática: para $98,4 \%$ dos estudantes, esse aprendizado deve ocorrer ainda durante a graduação, enquanto apenas 19,5\% acreditam que o momento certo para o ensino de UE seja durante a pós-graduação ou residência. Os estudos de Dias ${ }^{1}$, Aguiar et al. $^{8}$ e Fernandes ${ }^{18}$ corroboram esses achados. Esses autores descrevem a importância do ensino da UE ainda durante a graduação médica, determinando que ele deve ocorrer de forma ampla em todo o período e que é necessária ainda a participação ativa por parte do estudante a fim de elucidar tais ensinamentos em sua graduação.

Apesar de parte das respostas em relação ao tema ser assertiva, muitos dos estudantes ainda se sentem inseguros ou parcialmente seguros em relação ao aprendizado de UE na graduação médica, o que também foi constatado no estudo realizado por Dias ${ }^{1}$, em que a maioria dos estudantes considerou o ensino dessa matéria em sua instituição como inadequado às necessidades da graduação. Esses achados corroboram a necessidade de discutir mais o tema UE, dada a sua importância para a prática profissional.

Quanto à percepção dos acadêmicos no que concerne à própria formação, identificou-se diferença estatística nas questões relacionadas as temáticas triagem - Protocolo de Manchester, monitorização, SBV, SAV e emergências pediátricas, ao passo que não houve diferença nas referentes às emergências cardiovasculares, respiratórias, toxicológicas, neurológicas e endócrinas, ao atendimento ao politraumatizado e ao ensino de UE. Uma possível explicação está diretamente relacionada ao conteúdo, em que as diferenças nas percepções acontecem nas temáticas que ainda não foram totalmente apropriadas pelos períodos menos avançados, uma vez que, em todas as questões em que as diferenças foram significantes, os períodos avançados apresentaram as maiores proporções de que a formação foi adequada.

No âmbito do atendimento pré-hospitalar, o Brasil sofreu avanços em 2003 com a publicação da Política Nacional de Atenção às Urgências (Portaria do Ministério da Saúde no 1.863), cujo resultado foi a implantação do $S a m u^{5,16,19}$ que age no cuidado inicial e na estabilização de vítimas, bem como na triagem e no encaminhamento delas ao hospital adequado ${ }^{16}$. O Samu dispõe de dois tipos de ambulância - USB e USA ${ }^{17,20}$ - que se dividem de acordo com a gravidade do indivíduo (determinada pelo médico-regulador a partir das informações passadas pelo solicitante $)^{19}$.

Em relação ao funcionamento do Samu, a maioria dos estudantes tem conhecimento assertivo acerca da equipe e dos materiais integrantes de cada ambulância, bem como das principais causas que necessitam de atendimento desse serviço, enquanto as questões referentes à natureza das principais ocorrências e à população preconizada para uma USB e USA foram respondidas de forma incorreta pela maioria, pois se considerou que chamados de natureza traumática representam a maior parte de atendimentos e que a população preconizada é menor que dez mil habitantes para a USB e de 50 mil a 100 mil para a USA. Tais resultados refletem o que foi exposto por Horta et al. ${ }^{16} \mathrm{e}$ Fernandes et al. ${ }^{19}$ : a maioria dos estudantes do curso médico conhece a composição de materiais e profissionais das ambulâncias, porém as questões referentes às situações atendidas, à natureza delas e à população preconizada para a USB e USA são erroneamente respondidas. Isso demonstra uma evolução deste estudo em relação aos anteriormente citados e determina uma ampliação do conhecimento sobre a atuação do Samu nos últimos anos. O conhecimento relacionado à organização do Samu, como a escala populacional para o atendimento desse serviço, não é uma necessidade percebida, normalmente, pelos profissionais, talvez pelo fato de eles dedicarem-se às habilidades técnicas, associadas à sua profissão. No entanto, o conhecimento por parte dos profissionais dos aspectos relacionados à organização do serviço poderia facilitar o processo de gestão e melhorar a organização dos serviços por meio de uma participação mais efetiva deles.

O conhecimento a respeito dos profissionais que devem compor a USB e a USA foi estatisticamente maior nos acadêmicos dos períodos mais avançados. Esse resultado não representou nenhuma surpresa, pois, nos períodos mais avançados, a vivência nessas unidades é mais frequente com os estágios.

Conhecer as alternativas em que há necessidade de atendimento pelo Samu, a principal causa de atendimento pelo Samu, os ritmos cardíacos característicos de PCR que são chocáveis e a sequência de atendimento de emergência foi estatisticamente maior entre os acadêmicos mais avançados. Esse fato também pode ser explicado pelos mesmos motivos do item anterior. Por sua vez, o conhecimento do(s) sinal(is) clínico(s) de uma PCR, da relação correta entre compressões torácicas e ventilações em PCR em adultos assistida por dois socorristas e da frequência recomendada por minuto de compressões torácicas em vítima de PCR não apresentou diferença entres acadêmicos, independentemente do período. Isso ocorreu provavelmente por tratar-se de questões elementares de SBV muito trabalhadas entre os acadêmicos desde os primeiros períodos do curso, não concorrendo para diferença quando são comparados períodos mais avançados entre si. 
Situações de risco iminente de morte, como PCR, politrauma, infarto agudo do miocárdio (IAM), afogamento, entre outras, exigem reconhecimento e intervenção imediatos, o que leva à importância do conhecimento acerca do SBV e SAV ${ }^{1,17,21}$. No entanto, esse reconhecimento não tem sido precoce como deveria, por causa da falta de embasamento teórico associada à baixa prática acerca de UE. Sabe-se que a extensão dos conhecimentos desse tema à população leiga permite que mais pessoas possam ser salvas em cenas de risco. Porém, se há deficiência na formação de profissionais da área da saúde, torna-se mais difícil ampliar os saberes para o restante da população. Até mesmo a implantação da disciplina de UE em todos os cursos universitários, não apenas nos da área da saúde, poderia ser uma medida eficaz nesse sentido ${ }^{9,22,23}$. Quando se comparou este trabalho com os estudos de Lemos, Nisiyama, Farias e Hamann ${ }^{9}$, Oliveira, Santos e Zeitoun ${ }^{17}$, Santos et al. ${ }^{22}$ e Santos, Gonçalves, Aparecida, Bruzi e Santos ${ }^{23}$, percebeu-se uma grande discrepância nos resultados apresentados, pois, segundo esses autores, o ensino do SBV ainda se mostrava muito deficiente entre acadêmicos da saúde e leigos da sociedade brasileira.

Não houve diferenças estatísticas quanto à percepção da importância do conhecimento do médico generalista sobre UE. Percebe-se um consenso entre os grupos em considerar muitíssimo importante o conhecimento generalista do médico nas ocorrências de UE. No entanto, num aspecto que remete a uma impressão contrária à importância dada ao conhecimento relativo à UE, também sem diferença entre os grupos, a maioria dos acadêmicos não havia realizado atividade extracurricular em UE.

A ampliação das áreas de ensino, como uma abordagem mais ampla e fragmentada em vários momentos do curso, em vez da concentração do ensino no internato, assim como uma abordagem mais sistematizada que inclua áreas como as de urgências toxicológicas, pediátricas e formação em Protocolo de Manchester, que foram consideradas inadequadas pelos estudantes, pode resultar em maior efetividade do ensino de UE. A participação em atividades extracurriculares parece ter impacto positivo sobre essas questões, como mostram Tedeschi et al. ${ }^{24}$ que avaliaram o efeito de atividades oferecidas por uma liga acadêmica de UE de outra instituição e constataram melhora no desempenho dos estudantes. Além disso, assim como foi proposto por Flato e Guimarães ${ }^{10}$, Ruesseler et al. ${ }^{12}$ e Guedes et al. ${ }^{15}$, o ensino de UE poderia ser feito baseado em simulação de situações reais, a fim de que os alunos pudessem consolidar de forma prática aquilo que já sabem na teoria e, portanto, tornar-se mais seguros e aptos para a formação médica e atuação na UE. Afinal, a simulação permite prática segura e atenua a tensão ética envolvida quando se trata de vidas em momentos que exigem atuação rápida e definitiva ${ }^{18,25}$, mais bem conduzidos, portanto, por profissionais experientes ${ }^{18}$.

Após a conclusão do curso, não houve diferença significante entre os grupos em relação aos locais em que os graduados gostariam de trabalhar, com exceção da ESF. Os acadêmicos mais próximos da conclusão do curso apresentaram maior interesse nesse campo de trabalho, ao passo que os períodos menos avançados têm esse interesse mais distanciado. Uma explicação possível para esse fato é a visão histórica do profissional independente, autônomo e clínico, um estereótipo ainda vivido mesmo nos tempos atuais, em que o modelo flexneriano de atenção à saúde tem recuado em detrimento da produção social da saúde. Nesse sentido, nos períodos finais, nos estágios avançados, a vivência na ESF aumenta a percepção da potência desse campo de trabalho. Devem-se considerar ainda a atual crise econômica e a saturação do mercado de trabalho que alcança hoje todas as profissões, sobretudo nos grandes centros e nas regiões mais desenvolvidas. Nesse contexto, a ESF, que tem se desenvolvido e ampliado, consolida-se como um polo de atenção e também de interesse dos profissionais de saúde.

Entre as limitações deste estudo, destaca-se o fato de não avaliar se os estudantes que participavam de atividades extras acerca do tema desta pesquisa estavam mais aptos para atuar na área, além da reduzida amostragem. Porém, a avaliação global do ensino é válida, pois torna evidente a percepção de que os estudantes da instituição em questão já entram no internato e no pré-internato aptos para atender pacientes em situação de UE, ainda que não se sintam seguros para tal.

Com base nos resultados obtidos, constata-se que são fundamentais a manutenção, consolidação e ampliação do ensino com estímulo aos estudantes, para que eles se tornem mais aptos e seguros na atuação como profissionais. Esse dado não foi aferido neste estudo, mas observase que cursos de aperfeiçoamento extracurriculares, como Advanced Cardiovascular Life Support (ACLS) e Basic Life Suport (BLS), podem contribuir para o melhor aprendizado teórico-prático entre os alunos de Medicina, preparando-os para o cenário real que encontrarão na vida profissional $^{2}$. Háainda a necessidade de convergência de esforços para tornar a medicina de emergência uma especialidade médica, fato que já ocorre em países desenvolvidos ${ }^{1}$, de modo a formar profissionais capacitados para o ensino nessa área e melhorar a qualidade dos atendimentos, com consequente melhoria nos índices de morbimortalidade de pacientes em situações de risco iminente de morte ${ }^{1,5}$.

\section{CONCLUSÃO}

O ensino de UE na instituição avaliada tem se apresentado efetivo quanto ao objetivo de aprendizado do SBV e SAV, assim como do Samu na percepção dos acadêmicos, no entanto apresenta lacunas em relação ao conhecimento sobre a política de UE relacionada ao Samu e a epidemiologia dos atendimentos pré-hospitalares realizados por esse serviço, a avaliação e conduta durante $o$ atendimento.

Diversas áreas de abrangência do conhecimento desse tema, como urgências pediátricas e toxicológicas, ainda são percebidas como inadequadas pelos estudantes avaliados, o que denota a necessidade de adequação da formação dos alunos a essa temática. O ensino é percebido por grande parte dos acadêmicos como parcialmente adequado, o que pode refletir nos acertos parciais relacionados ao conhecimento sobre rede, epidemiologia, avaliação e conduta na UE. Um cenário desse tipo pode provocar insegurança nos acadêmicos. Para reverter tal situação, sugerese a ampliação dos momentos de prática do ensino de UE, que deveria acontecer mais precocemente no curso, haja vista que os acadêmicos em estágio avançado apresentaram, em muitos pontos, mais acertos em relação aos vários domínios pesquisados.

\section{REFERÊNCIAS}

1. Dias NS. Percepção dos alunos do nono semestre de graduação sobre o ensino de urgência e emergência na Faculdade de Medicina da Bahia [monografia]. Salvador: Faculdade de Medicina da Bahia; 2016.

2. Feitosa Filho GS, Kirschbaum M, Neves YCS, Loureiro BMC, Lima VACC, Calazans RM, et al. Characteristics of training and motivation

REVISTA BRASILEIRA DE EDUCAÇÃO MÉDICA

7 44(3): e075; 2020 
of physicians working in emergency medicine. Rev. Assoc. Med. Bras. 2017;63(2):112-7.

3. Das M, Elzubeir M. First aid and basic life support skills training early in the medical curriculum: curriculum issues, outcomes, and confidence of students. Teaching and Learning in Medicine: An International Journal 2001;13(4):240-6.

4. Stewart NH, Tanksley A, Edelson DP, Arora VM. Trainees at a resuscitation: a dual liability. The Clin. teach. 2017;13:1-6.

5. Fraga GP, Pereira Júnior GA, Fontes CER. O ensino de urgência e emergência nos cursos de graduação de medicina: situação atual e recomendações para a matriz curricular. In: Lampert JB, Bicudo AM, organizadoras. 10 anos das Diretrizes Curriculares Nacionais do Curso de Graduação em Medicina. Rio de Janeiro: Associação Brasileira de Educação Médica; 2014. p. 41-56.

6. Fraga GP, Quintas ML, Abib SCP. Trauma e emergência: o SUS é a solução no Brasil? [editorial]. Rev. Col. Bras. Cir. 2014;41(4):232-3.

7. Campos MSG, Senger MH. Avaliação do estágio de urgências clínicas em uma unidade de pronto atendimento sob a perspectiva dos alunos. Rev. bras. educ. med. 2014;38(1):103-12.

8. Aguiar HDG, Dias VL, Lage LF, Madad Filho A, Gama PO, Gonzaga DM, et al. O ensino da medicina de urgência no Brasil. Rev. méd. Minas Gerais 2011;21(4 supl 6):S1-S143.

9. Lemos EFL, Nisiyama AL, Farias IEC de, Hamann EM. Educação em saúde: a experiência de alunos de Medicina no ensino em primeiros socorros. Participação 2012;20:35-42 [acesso em 12 maio 2017]. Disponível em: periódicos.unb.br.

10. Flato UAP, Guimarães HP. Educação baseada em simulação em medicina de urgência e emergência: a arte imita a vida. Rev. Soc. Bras. Clín. Méd. 2011;9(5):360-4.

11. Fraser K, Wright B, Girard L, Tivorek J, Paget M, Welikovich L, et al. Simulation training improves diagnostic performance on a real patient with similar clinical findings. Bull. Am. Coll. Chest Phys. 2011;139(2):376-81.

12. Ruesseler M, Weinlich M, Muller MP, Byhahn C, Marzi I, Walcher F. Republished: simulation training improves ability to manage medical emergencies. Postgrad. med. j. 2012;88:312-6.

13. Naidoo M. An evaluation of the emergency care training workshops in the province of KwaZulu-Natal, South Africa. Afr. j. prim health care fam. med. 2017;9(1):1277-83.

14. Melo MCB, Silva NLC, Liu PMF, Cerqueira Filho LC, Gresta MM, Santos AF. E-Learning and simulation on a pré-hospital emergency course: a participant's perspective. Rev. bras. educ. med. 2016;40(4):713-9.

15. Guedes MHC, Gomes JTS, Almeida ASR, Bonfim ALDL, Vilela LFF, Côrtes PPR. Uso de simulação no ensino de urgência e emergência pré-hospitalar para discentes de medicina: relato de experiência. Rev. Saúde (vassouras) 2017;8(1):8-14.

16. Horta BL, Pereira GAS, Silva AB, Resende PHA, Rosenthal RM, Comin $\mathrm{C}$, et al. Conhecimento do estudante de Medicina sobre o Serviço de Atendimento Móvel de Urgência. Rev. AMRIGS 2011;55(1):20-4
17. Oliveira SS, Santos JO, Zeitoun SS. Suporte básico de vida: avaliação do conhecimento dos graduandos de enfermagem. Revista do Instituto de Ciências da Saúde 2014;32(1):53-8.

18. Fernandes CR, Falcão SNRS, Gomes JNA, Colares FB, Maior MMMS, Correa FV, et al. Ensino de emergências na graduação com participação ativa do estudante. Rev. bras. educ. med. 2014; 38(2):261-8.

19. Fernandes CR, Cavalcante SB, Pinheiro JA, Costa JVC, Costa PLR, Melo Filho AA. Conhecimento de estudantes de Medicina sobre o funcionamento do Serviço de Atendimento Móvel de Urgência (Samu). Rev. bras. educ. med. 2014;38(2):253-60.

20. Brasil. Ministério da Saúde. SAMU-192: O que é o SAMU? [acesso em 10 maio 2017]. Disponível em: http://portal.saude.gov.br/portal/ saude/visualizar_texto.cfm?idtxt $=30273$ \&janela $=1$.

21. Bezerra YCP, Matos GSS, Costa JS, Medeiros RLMF. Multiple trauma: knowledge of nursing students about assistential practices. Journal of Nursing UFPE 2015;9(11):9817-25.

22. Santos SV, Margarido MRRA, Caires IS, Santos RAN, Souza SG, Souza JMA, et al. Basic life support knowledge of first-year university students from Brazil. Braz. j. med. biol. res. 2015; 48(12):1151-5.

23. Santos GAB, Gonçalves TSP, Aparecida F, Bruzi FAF, Santos AC. Conhecimentos básicos sobre suporte básico de vida (SBV) em estudantes universitários. Revista Eletrônica FACIMEDIT 2016;5(1).

24. Tedeschi LT, Rigolon LPJ, Mendes FDO, Fischmann MM, De I, Klein A, et al. A experiência de uma liga acadêmica: impacto positivo no conhecimento sobre trauma e emergência. Rev. Col. Bras. Cir. 2018;45(1):e1482.

25. Bettega AL, Brunello LFS, Nazar GA, De-Luca GYE, Sarquis LM, Wiederkehr HA, et al. Simulador de dreno de tórax: desenvolvimento de modelo de baixo custo para capacitação de médicos e estudantes de medicina. Rev. Col. Bras. Cir. 2019;46.

\section{CONTRIBUIÇÃO DOS AUTORES}

Érica Manuela da Silva Boa Sorte e Jéssica Novais Fonseca da Silva foram responsáveis pela conceituação do trabalho, curadoria de dados, análise formal, investigação, metodologia e redação (rascunho original, revisão e edição). Carlos Gabriel dos Santos e Paula Dandara Correia de Pinho participaram da revisão e edição (suporte) do artigo. Jairo Evangelista Nascimento participou da revisão e edição (suporte) do artigo e da análise estatística. Claudiojanes Reis participou da investigação (suporte), da revisão e edição (suporte) do artigo e da análise estatística.

\section{CONFLITO DE INTERESSES}

Os autores declaram não haver conflito de interesses neste estudo.

\section{ENDERECO PARA CORRESPONDÊNCIA}

Claudiojanes Reis. Rua Padre Eustáquio, 336, Bairro São José, Montes

Claros, MG, Brasil. CEP: 39400-345.

E-mail: claudiojanes@yahoo.com.br 